\title{
Risk communication and public engagement in CCS projects: the foundations of public acceptability
}

\author{
William Leiss* and Patricia Larkin \\ McLaughlin Centre for Population Health Risk Assessment, \\ University of Ottawa, \\ Room 216A, 600 Peter Morand Crescent, \\ K1G 5Z3, Ottawa, Ontario, Canada \\ Email: leissw@queensu.ca \\ Email: plarkin@xplornet.com \\ *Corresponding author
}

\begin{abstract}
This paper posits that an important goal of public engagement for carbon capture and storage (CCS) projects as being public and social acceptance for those projects. It argues that acceptability is the end of a long, logical chain of social interactions, which ideally starts with: 1) the public perception of the risks and benefits associated with CCS; moves through 2) effective communication of risks and benefits by project proponents; 3 ) involves robust and credible measures for public engagement; 4) results in authoritative decision processes that transparently reflect the results of engagement. Each of these components of acceptability is described with respect to both actual experience with CCS projects to date and the relevant literature. Conclusions point to the special importance of full transparency and public understanding of credible risk assessments for these projects.
\end{abstract}

Keywords: risk perception; benefit perception; risk communication; public engagement; stakeholder engagement; decision processes; public acceptability.

Reference to this paper should be made as follows: Leiss, W. and Larkin, P. (2019) 'Risk communication and public engagement in CCS projects: the foundations of public acceptability', Int. J. Risk Assessment and Management, Vol. 22, Nos. 3/4, pp.384-403.

Biographical notes: William Leiss is a Fellow and Past-President (1999-2001) of the Royal Society of Canada and an Officer in the Order of Canada. $\mathrm{He}$ is currently a scientist at the McLaughlin Centre for Population Health Risk Assessment, University of Ottawa. From 1999 to 2004, he held the NSERC/SSHRC/Industry Research Chair in Risk Communication and Public Policy at the Haskayne School of Business, University of Calgary. From 1994 to 1999, he held the Eco-Research Chair in Environmental Policy at the Queen's University (Ontario). He is the author of Risk and Responsibility (1994), Mad Cows and Mother's Milk: The Perils of Poor Risk Communication (1997, 2004), in the Chamber of Risks: Understanding Risk Controversies (2001), all from McGill-Queen's University Press.

Patricia Larkin is a Post-Doctoral Fellow at the University of Ottawa. Her field of research, population health, considers structural and intermediary determinants of health and their interactions, with a goal to protect or improve human health. With a focus on applied risk management in the energy, genomics, and public health sectors, she is undertaking research, writing and project management at the McLaughlin Centre for Population Health Risk 
Assessment and the Institute for Science Society and Policy. She is an active member of the Society for Risk Analysis. She holds her Master's in Geography and Graduate Diploma in Population Health Risk Assessment and Management.

\section{Introduction}

This paper is focused on the interaction of a set of factors that are regarded as being a key component in the feasibility of carbon capture and storage (CCS), including its four value chain components of capture, transportation, injection and storage. Along with other dimensions such as technological feasibility, competent regulatory oversight, acceptable economic costs and supportive public policy frameworks (Leiss and Krewski, 2019), social acceptability is one of the dimensions that will determine whether CCS will live up to the original expectation that was set for it almost fifteen years ago.

This expectation may be phrased as follows: If a sufficient number of large-scale CCS projects are put in place around the world, with new ones coming into play as earlier ones are completed, all together they will make a significant contribution to meeting stated greenhouse-gas (GHG) control targets. Current targets are based on the Paris Agreement objective of holding global average temperature increases at or below +2 degrees C (UNFCCC, 2015). Specifically, CCS is expected to contribute to $12 \%$ of the total emissions reduction in 2050, a key contributor to global emissions reductions (IEA, 2016). Annual emissions reductions could equal $8 \mathrm{Gt} / \mathrm{CO}_{2}$ by 2050 , requiring over 3000 CCS projects operating worldwide in both developed and developing countries [CCSA, (2012), p.1]. The total costs are measured in the trillions of dollars (IEA, 2010).

In this paper we will be concentrating only on the social acceptability of CCS. Its key importance has been well-identified by one of the leading sponsors of research in this area, Australia's national science agency, the Commonwealth Scientific and Industrial Research Organisation, which stated in its 2013 summary of CCS social research: 'Public acceptance of carbon capture and storage technology has been identified as a potential showstopper for its development and deployment' [Ashworth et al., (2013), p.vi]. A journal article reiterated this observation [Ashworth et al., (2012), p.402): 'CCS is still very much at a developmental stage and the full-scale projects required to test the technology have proven difficult to implement, with lack of societal acceptance considered a key contributing factor to this delay.' In additional studies (Bäckstrand et al., 2011; Kefford et al., 2018; Shackley et al., 2009), levels of perceived risks and low awareness about CCS were cited as key barriers to CCS deployment by advocates in industry, government and the NGO sector.

CSIRO's summary report (Ashworth et al., 2013) looked at a total of 900 publications and chose for further analysis the 14 articles that were cited by others three or more times; this set was then combined with a content analysis of 25 reports issued by the Global CCS Institute, for a total of 39 key outputs, within which seven core themes were identified:

1 Framing: CCS projects should be presented within the broader contexts of energy policy and climate change policy, rather than as advocacy for CCS as a standalone technology. 
2 Local context: All CCS projects have a specific storage location and therefore intense involvement of local communities is essential.

3 Trust: "Not just trust in the capability of operators to carry out CCS safely, but also trust in the motivations of those delivering the CCS message... will influence the levels of risk an uninformed public perceives in relation to a project."

4 Communication and engagement processes: Both early engagement and a 'high level' commitment of engagement and communication resources, using experienced professionals, are important.

5 Information: Again, presentation of information within the wider energy and climate change context is essential.

6 Risk perception: Attention should be paid to the specific, local risk perception factors.

7 Governance: “...[T] processes of the CCS chain and transparent and fair processes are critical."

The large literature database out of which these priority themes were extracted lends this summary a high degree of authority.

\subsection{Analytical framework: the social acceptability continuum}

This paper proposes that four determinants of acceptability have to be understood in their logical relationships with each other, rather than in isolation; also, part of this logic is that the sequence across the continuum is fixed - that is, earlier steps must precede later ones. The four determinants are:

1 understanding risk and benefit perception among stakeholders and the public

2 practising effective risk and benefit communication, including information provision under conditions of full transparency

3 undertaking meaningful stakeholder engagement

4 developing fair and robust decision processes.

Then, all of the foregoing need to 'come together' in the final outcome:

1 public and social acceptability.

Taken together, the dynamic nexus in which these factors interact may be called the construction of social acceptability. Meaningful stakeholder and public engagement may be regarded as the bridge, or mediating phase, between risk perception and communication, on the one hand and, on the other, credible decision processes which may lead to the final objective of public and social acceptability. In other words, there is a continuum along which may be arrayed the components of acceptability, as follows:

\begin{tabular}{lcccc}
\hline Step 1 & Step 2 & Step 3 & Step 4 & Step 5 \\
\hline Risk/benefit & Risk/benefit & Stakeholder & Decision & Public/social \\
Perception & Communication & Engagement & Processes & Acceptability \\
\hline
\end{tabular}


Ideally, along this continuum, accurate current knowledge about the public perceptions of the risks and benefits associated with CCS (Step 1) will be integrated into outreach programs using awareness of effective communication and dialogue processes, including provision of relevant information, about the risks and benefits of CCS as assessed by competent and trustworthy authorities (Step 2). These communication processes will occur within a network of public engagements (Step 3), with all interested groups and individuals, involving a variety of settings - open meetings, web-based resources with interactive components, social media and others. These engagements should occur within a larger context of robust decision processes (Step 4), wherein the individuals and groups who have been engaged in the dialogues can see clearly how their inputs have been taken into account by decision-makers.

Finally, all this may lead to public acceptance of CCS (Step 5), both at the local level, with respect to facility siting and at the national level, with respect to broad public support for a policy framework. With respect to the latter, the costs and risk/benefit tradeoffs of CCS would necessarily be endorsed over the long time-frame which CCS requires in order to realise its core objective in reducing GHG emissions around the world. Meeting this objective entails planning, constructing and operating literally hundreds - and eventually several thousand - major CCS projects across the nations and regions where GHG emissions are now and are expected to remain for the foreseeable future (IEAGHG, 2017).

Actual acceptability will be won or lost over the long term on both the local and the multi-national fronts: Since each project necessarily requires an individual, successful siting process, the local arena will be heavily involved in all of them. And the overall prospects for CCS is entirely dependent on the success of a set of many concurrent national policies that are regarded as allocating risk, costs and benefits fairly.

In the following pages each of the five elements along the continuum are explored in some detail. The special case regarding communication and transparency in risk assessment and risk management is also addressed. It should be said at the outset that $\mathrm{CCS}$ is unique, as a new technology and policy initiative of global dimensions, in that both industry and governments have devoted significant resources, at an early stage, to the social dimensions of this initiative. This is particularly true in three areas - public perception studies, communication and outreach guidelines and stakeholder engagement protocols.

\section{Risk and benefit perception}

CCS is an unusual case in this regard, in that the perception of benefits - or the failure to appreciate the benefits of CCS - may be more important than perception of risks (the normal case is the exact opposite). As L'Orange Seigo et al. (2014, p.31) explain: “It seems that the public is not overly frightened about potential risks of CCS but exhibit higher levels of uncertainty about the role it may play in the mitigation of climate change." Indeed, most studies and surveys have focused on the general acceptability of CCS as a mitigation strategy. And yet even this opinion research has been met with some criticism because the knowledge base of respondents is generally low, thereby leading to responses that are not necessarily based on informed opinion (Wallquist et al., 2012).

The low information base of survey respondents for CCS has been confirmed in many studies [e.g., de Best-Waldhober et al., (2012), p.S147], which shows that the information 
deficit extends to the most basic scientific findings about $\mathrm{CO}_{2}$ itself, even in a national population that otherwise might be regarded as knowledgeable:

\begin{abstract}
"This study illustrates the nature and magnitude of doubts and knowledge gaps among the general Dutch public regarding our energy system, $\mathrm{CO}_{2}$, climate change and CCS. Only very few people understand how our current use of fossil fuels leads to $\mathrm{CO}_{2}$ emissions which in turn lead to climate change, even though almost all people state to know about global warming. The test revealed several misconceptions that were shared by a major percentage of the respondents..."
\end{abstract}

These interesting findings were also reported in much greater detail, in the context of a major 2012 report on survey respondents across Japan, Australia and the Netherlands (Itaoka et al., 2012). Many useful examples of the limited knowledge and misconceptions about carbon dioxide itself and the impact of these factors on the consequent lack of understanding of CCS and its purpose, are provided in this report.

National surveys conducted in 2011 across a wide swath of European countries, as well as in Canada, had similar findings. The IPACCO2 (2011a) survey of public awareness and acceptance of carbon capture and storage in Canada concluded: "Overall, $14 \%$ of Canadians have heard of CCS and know what it is, while a further $30 \%$ have heard of CCS but don't know what it is... Provincially, respondents from Saskatchewan $(40 \%)$ and Alberta (27\%) are the most likely to have heard of CCS and know what it is, while respondents from Atlantic Canada (10\%) and Ontario (9\%) are least likely." The European Commission's 2011 Eurobarometer survey on public awareness and acceptance of $\mathrm{CO}_{2}$ capture and storage, which covered twelve out of twenty-seven EU nations, reported (European Commission, 2011) that:

- Only one in ten (10\%) said they had heard of CCS and knew what it was; a further one in five (18\%) had heard of it but did not really know what it was.

- Just under nine out of ten (88\%) respondents in six countries where there is a major EU co-financed CCS project, when asked if they had heard of the project in their country, said they had not.

- A high proportion of respondents (38\%) felt that they 'would not benefit' from CCS technology if it was used in their region.

- Generally, people would be concerned about CCS technology if an underground storage site for $\mathrm{CO}_{2}$ were to be located within $5 \mathrm{~km}$ of their home: $61 \%$ said they would be worried, of which just under a quarter $(24 \%)$ said they would be 'very worried'.

Finally, in 2013 the European Commission issued a sobering update on the situation, observing that the continuing low level of both information and acceptance of CCS was having a decisive effect on the EU's attempts to site and operate demonstration projects: "Some projects that envisage onshore storage face strong public opposition... Despite much effort and significant EU support, CCS commercial scale demonstration projects in the EU are delayed and available funding is not sufficient" [European Commission, (2013), p.18].

A study of CCS perceptions in four US states (Massachusetts, Minnesota, Montana and Texas) reveals another aspect of the perceived benefits conundrum with respect to CCS (Chaudhry et al., 2013). The authors noted a frequent failure to mention reduction of 
$\mathrm{CO}_{2}$ emissions in response to open-ended questions about the rationale for undertaking CCS projects and hypothesised that the potential benefit of emissions reduction is being 'offset' by a view of CCS as a 'fossil-fuel-perpetuating technology' which will prolong society's dependence on this energy source, thus inhibiting the development of alternative energy forms. This same result also appears in a study of public attitudes in the three provinces of Western Canada (British Columbia, Alberta and Saskatchewan [L'Orange Seigo et al., (2014), p.31], where "concerns that CCS might be perceived as 'the' solution to climate change and divert funds away from renewable energy technologies" were heard. Boyd et al. (2017) reported on a national survey conducted in Canada in 2010, at which time there was low support for CCS development and funding when models took into account risk perception, views on climate change and trust in government (but with variable findings when proximity to a project was taken into account).

Where general risks have been identified, Mander (2011) and agencies such as the IEA and GCCSI have found the greatest risks to be associated with regulation, governance, finance and generally with the basic CCS concept itself. In those studies where the focus is on the dimensions of perception towards the health and environmental risks emanating from the components of the CCS value chain, discussion remains at a high level; for example, Johnsson et al. (2009) report that citizen's panels in the US, Japan and Europe identified a few risks of common concern - transport, handling, leakage and seismic activity. In EU countries, the above noted 2011 Eurobarometer survey found the two main concerns to be 'effects on the environment and health' and the 'risk of leaks while the site was in operation.' Worldview and beliefs about local benefits of a CCS project and concerns for safety, were found to have the greatest impact on an increase or decrease in acceptance of a nearby facility in coal-intensive Indiana (Krause et al., 2014).

The results of the Project Pioneer opinion survey on local community perceptions in Alberta (GCCSI, 2011) cited the most frequent main concerns or drawbacks as potential leaks or ruptures, the cost and possible unknown long term effects. In a study on the views of experts in Spain, six primary risks were highlighted: accidents in power plants, seismic activity due to $\mathrm{CO}_{2}$ storage, impacts on water reservoirs, the effects of leakage from storage on ecosystems, human health impacts and pipeline failures (Sala and Oltra, 2011). L'Orange Seigo et al. (2014, p.30), reporting results from the three Canadian western provinces also found low knowledge about CCS and correctly concluded: "It is certainly necessary to educate the public about $\mathrm{CO}_{2}$ and $\mathrm{CCS}$, because knowledge is a prerequisite for making informed decisions and knowledge was generally low in our sample". And they also make the important point connecting risk and benefit perceptions to the next phase along the acceptability continuum: "This insight can help to structure risk communication materials and tailor them better to their audience."

\section{Risk/benefit communication and information provision}

As noted previously, there are two scales of activities for the challenge of monitoring risk perceptions and doing credible risk communication activities: At the project level, where the highest risks and uncertainties may exist in the local community when capture, transport, injection or storage exists or is proposed; and at the regional, national or even international level, when CCS technology is discussed as a global $\mathrm{CO}_{2}$ mitigation option. 
A direct result of the findings about severe $\mathrm{CO}_{2}$ and CCS information deficits, reflected in the perception studies referred to above, should be obvious: namely, that a very significant effort in communication and information provision in these areas is essential. Ashworth et al. (2010a) suggested that there are four audiences in CCS communications activities: influential others, wider community members and groups, educational institutions or groups and project-specific stakeholders.

However, for the period 2002-2009, Ashworth et al. (2010b, p.430) reviewed 33 case studies of CCS related communication and research activities and noted that "overall the expenditure in the area of communication and public awareness has been insignificant when compared with the allocated budgets of the CCS technological research and development programs". The majority of programs were designed to inform researchers, policy and environmental NGOs and local stakeholders. Relatively little communication activity has targeted the general public.

Perhaps in response to this relative neglect, the Global Carbon Capture and Storage Institute sponsored the preparation of two practical guidebooks for risk communication on CCS, the Communication/Engagement Toolkit for CCS Projects (Ashworth et al., 2010a) and Communicating the Risks of CCS (Bradbury et al., 2011). A later report from the same organisation (GCCSI, 2013), entitled Communications for carbon capture and storage: Identifying the benefits, managing risk and maintaining the trust of stakeholders, reviews the communication approaches of five CCS projects and explores the common challenges and themes they faced. It notes that potential failure to gain 'public acceptance' is one of the key risks facing CCS demonstration projects, in conjunction with 'regulatory uncertainty' and 'funding challenges'. It identifies a 'CCS image crisis' involving the following factors:

- The large, international scale of the enterprise and its individual facilities

- The fact that it will not result in a noticeably cleaner environment

- The perception that it facilitates prolonged use of fossil fuels

- A poor understanding of technology and geology.

The report further recommends a conceptual framework of balancing benefit, truthfulness and assurance in order to gain stakeholder approval.

Where the risk issue itself is relatively new and thus unfamiliar to the public (as is the case with CCS) and also involves deployment of an interlinked set of emerging technologies (carbon capture, compression to a supercritical state, injection and the long-term safe sequestration of massive volumes of $\mathrm{CO}_{2}$ deep underground ${ }^{1}$ ), the requisite level of transparency assumes a highly significant role in public understanding and acceptance. The importance of this aspect of risk communication has been well-recognised. For example, the 2012 CSA Standard for CCS stipulates that risk communication and consultation should specifically address the thoroughness, accuracy, transparency, traceability and consistency of the risk assessments and the nature and degree of understanding of known or perceived risk scenarios (CSA, 2012).

We can best appreciate current communications and outreach materials by briefly examining and describing the web-based content of some major CCS projects in Canada and elsewhere.

The Weyburn-Midale enhanced oil recovery project in southern Saskatchewan uses $\mathrm{CO}_{2}$ from a coal gasification plant in North Dakota that is sent by pipeline across the 
border, as well as from SaskPower's Boundary Dam coal fired electricity station. It has been operating since 2000 and injects $\sim 8000$ tonnes per day underground. As of the time of writing, the most complete and current independent website for this project, including an account of the controversy in 2011 over alleged leaking of the stored carbon at the Kerr farm, is the Wikipedia entry (http://en.wikipedia.org/wiki/WeyburnMidale_Carbon_Dioxide_Project). A local landowner alleged in January 2011 that $\mathrm{CO}_{2}$ was leaking onto the surface of his property from the underground repository; a study commissioned by an arm's-length environmental monitoring organisation used isotopic analysis to argue that the gas was of natural origin in the surface locality, see Boyd et al. (2013) for extensive quotations from media accounts and initial expert reactions. There is no mention of this controversy in an otherwise fine 2014 information booklet with good graphics (no longer posted online), What Happens When CO2 Is Stored Underground: Q\&A from the IEAGHG Weyburn-Midale $\mathrm{CO}_{2}$ Monitoring and Storage Project. The project reference on the website operated by the Petroleum Technology Research Centre (PTRC, 2019) is also silent about the controversy. On the other hand, the initial Weyburn-Midale project operators, Cenovus Energy, continue to feature its report and press release on its own investigation into the allegations, both from November 2011, on its company website (Cenovus Energy, 2014).

The Boundary Dam Integrated Carbon Capture and Storage Demonstration Project, at a coal-fired generating station operated by SaskPower in Saskatchewan, will combine both EOR and a small scale sequestration-only storage project (operated by the PTRC). In a press release from April 2014, announcing a collaboration agreement on CCS between SaskPower and the large German energy firm Vattenfall, the Boundary Dam project was described as "the first commercial post-combustion carbon capture system in the world," which is expected to result in 1 million tonnes/year reduction in $\mathrm{CO}_{2}$ emissions. At least initially, most of the $\mathrm{CO}_{2}$ will be sent by pipeline for EOR at the above mentioned Weyburn field, with some going to geological storage through a PTRC research project known as the Aquistore Project (http://aquistore.ca/). The sequestration is taking place "3.4-kilometres deep in a layer of brine-filled sandstone called the Deadwood Formation ... located near Estevan, Sask."

In Alberta, the Shell Quest Project is designed to capture 1 million tonnes/year of $\mathrm{CO}_{2}$ from Shell's Scotford Upgrader plant in Fort Saskatchewan, transport it by pipeline $80 \mathrm{~km}$. north and inject it into a saline reservoir more than $2 \mathrm{~km}$. underground. The project website (Shell Canada, 2018) provides a video as well as text-based information. The Alberta Carbon Trunk Line Project is approved to capture $\mathrm{CO}_{2}$ from a number of industrial facilities in the industrial heartland and transporting it to EOR facilities via a $240-\mathrm{km}$. pipeline. The capacity is up to $14 \mathrm{MT} / \mathrm{year}$, which would make it one of the largest CCS project in the world; the initial phase, starting imminently, will capture and store 1.5MT/year. The project website (ACTL, 2018) has a good map and video.

In British Columbia, while still in the feasibility planning stage (GCCSI, 2018), the Fort Nelson Project (conceived by Spectra Energy, now Enbridge) is also designed to rank among the largest CCS projects in the world, capturing $\mathrm{CO}_{2}$ from a natural gas processing plant and by 2017 sequestering up to $3 \mathrm{MT} /$ year in a nearby deep saline carbonate rock formation. An interesting aspect of this project is that most of the up-front development funds were provided by the US Department of Energy (DOE, 2009), with additional funding from the Government of Canada's ecoEnergy Technology Initiative and the province of $\mathrm{BC}$. At the time of writing, multiple attempts to determine the status of the project were unsuccessful. 
In the US, the FutureGen Project involved a near-zero-emissions, coal-fired generating station designed to capture 1.1 million tons/year of $\mathrm{CO}_{2}$, transport it 30 miles by pipeline to a sequestration site and inject it 4,000 feet underground in a brine aquifer. In 2014, the project website was a good model for communication with the public on CCS projects; it included a fine graphic and written description of the specific geological formation chosen for the storage site, as well as a full account of the monitoring and verification protocol. The project is suspended, with US federal funding cancelled in 2015 .

In addition, it must be noted that Australia has been one of the most active countries in early CCS major project development (Cook, 2017), including the Gorgon Project (Chevron, 2018). When completed it is expected to be the world's largest commercial-scale $\mathrm{CO}_{2}$ injection facility, injecting up to $4 \mathrm{MT} /$ year of carbon dioxide in a reservoir $2 \mathrm{~km}$. beneath Barrow Island off the northwestern coast of Western Australia.

Attention has been paid to Norway's Sleipner field, the longest running commercial $\mathrm{CO}_{2}$ sequestration project operating since 1996, a second offshore project at Snøhvit (Eiken et al., 2011; Ringrose, 2018), as well as to the general topic of offshore, subsea sites for $\mathrm{CO}_{2}$ sequestration. This is a direct result of findings from a large EU-funded research venture, called $\mathrm{ECO}_{2}$, designed to study risks associated with storing $\mathrm{CO}_{2}$ beneath the seabed. The research utilised autonomous underwater vehicles using sonar and seismic profiling to penetrate the geological formations, asking questions such as: "Are there any high permeability pathways for gas and fluid flow cutting through the overburden and linking the storage formation to the seep sites discovered at the seabed? Are seepage rates amplified by the ongoing storage operation at Sleipner? May $\mathrm{CO}_{2}$ stored at Sleipner and elsewhere ultimately leak through the overburden via seismic pipe and chimney structures, fractures and abandoned wells?" The Sleipner field lies within the Utsira formation and the findings revealed previously-unknown horizontal and vertical fractures within the formation, near the storage site. There was discussion about the nature and significance of these findings with respect to the long-term security of the site (Monastersky, 2013). At the time of writing, the sequestration project operator, Norway's Equinor (formerly Statoil), has no references at all to this discussion on its website and a new project is being developed to receive $\mathrm{CO}_{2}$ from several industrial sources (Equinor, 2018).

There is one other noteworthy failure in the trove of internet-based information on current CCS projects, namely, the account of the In Salah project in Algeria. Begun as an on-shore sequestration project connected to a gas field development in 2004 and eventually operated by three partners, Britain's BP, Norway's Statoil and Algeria's Sonatrach, injection was suspended in 2011 (and has not yet been resumed), as a result of concerns over leakage. Ringrose et al. (2013, p.6232) explain that

$$
\begin{aligned}
& \text { "... analysis of the reservoir, seismic and geomechanical data led to the } \\
& \text { decision to suspend } \mathrm{CO} 2 \text { injection in June } 2011 \text {. The future injection strategy is } \\
& \text { currently under review and the comprehensive site monitoring programme } \\
& \text { continues. Concerns about possible vertical leakage into the caprock led to an } \\
& \text { intensified R\&D programme to understand the geomechanical response to } \mathrm{CO}_{2} \\
& \text { injection at this site..." }
\end{aligned}
$$

This problem is flagged in the project page on a Massachusetts Institute of Technology (MIT, 2018) sequestration database, but the websites of the three industry partners do not have any clear and accessible information about it. (The three joint-venture partners also operate the Amenas gas field in Algeria, which was the location of a notorious terrorist 
attack in January 2013). Given the obvious general concern about leakage from CCS sequestration projects, this is a serious oversight. Ringrose et al. (2013) provides a good discussion of the risk assessment of the In Salah problem and Bui et al. (2018) make note of the pressure increase that caused the cap rock fracture but these are not easilyaccessible sources for members of the public.

\section{Stakeholder engagement}

In general, communication and outreach activities for a public policy issue such as CCS are closely related to stakeholder engagement strategies. This is because CCS is always and necessarily, in the first instance, a facility siting matter (leaving aside the national policy issue about $\mathrm{CO}_{2}$ mitigation). Thus it is interesting to note that in the area of stakeholder engagement for CCS a number of sophisticated and elaborate general guidance documents have been prepared by reputable bodies. These include, from the Institute for European Environmental Policy (2010, p.iii), the Review of the Public Participation Practices for CCS and non-CCS Projects in Europe:

"The European project NearCO2 is investigating European public perceptions of carbon capture and storage (CCS) via case studies, surveys and focus groups. The overall aim of the project is to investigate and develop communication strategies that are designed to convey the advantages and risks of CCS to stakeholders and to the public, as well as which strategies may be used to involve these parties in local decision-making on CCS projects."

The World Resources Institute (2010), a well-regarded public-interest organisation, prepared its Guidelines for Community Engagement in Carbon Dioxide Capture, Transport and Storage Projects. This provides both highly-credible principles and very detailed practical suggestions for those who are responsible for carrying out public engagement programs detailing the risks and benefits of CCS projects.

The US Department of Energy's National Energy Technology Laboratory is an important actor among public-sector organisations which are doing planning and development work for CCS projects. It published a Revised Edition of a detailed guidebook issued in 2009 and again in 2013, Best Practices for Public Outreach and Education for Geologic Storage Projects (NETL, 2017) that reflects actual experience from its regional carbon sequestration partnership (RCSP) activities (see also Daly et al., 2011). "The primary lesson learned from the RCSPs' experience is that public outreach should be an integral component of project management. Although conducting effective public outreach will not necessarily ensure project success, it can make important contributions to schedule adherence, cost controls and community goodwill" [NETL, (2017), p.44). (The 2013 text suggested that: 'underestimating its importance can contribute to delays, increased costs and community ill will'). The booklet contains guidance in the following specific areas:

- Best Practice 1: Integrate public outreach with project management.

- Best Practice 2: Identify outreach goals with project management.

- Best Practice 3: Establish a strong outreach team.

- Best Practice 4: Identify key stakeholders. 
- Best Practice 5: Conduct and apply social characterisation.

- Best Practice 6: Establish an outreach program.

- Best Practice 7: Develop key messages.

- Best Practice 8: Develop outreach materials tailored to the audiences.

- Best Practice 9: Implement and manage the outreach program.

- Best Practice 10: Assess the performance of the outreach program.

- Best Practice 11: Be flexible - adapt the public outreach program as needed.

Continued attention to best practices in stakeholder engagement for CCS projects is underscored by the case of a significant siting failure in the Netherlands in 2010. Shell operates a refinery in the town of Barendrecht and in 2007 - in response to a tender issued by the Dutch government - the company proposed to capture $\mathrm{CO}_{2}$ emissions from the refinery and store the carbon in an on-shore depleted natural gas reservoir over a period of 25 years; the government had allocated $\$ 39$ million in public money to support the project. However, strong local opposition emerged, quite unexpectedly, leading not only to the cancellation of this specific project, but also to a decision by the government against approving any further on-shore underground CCS storage projects. A detailed study of the development of the public controversy (Feenstra et al., 2010; see also Brunsting et al., 2010; Terwel et al., 2012) identified many failures in the communications process between proponents and the local community, as well as corresponding failures in the outreach activities. For example, when the community first learned about the project, it was presented to them as a fait accompli, that is, as already agreed to between the company and the national government. The extensive, detailed section in the excellent Feenstra (2010) study What Happened at Barendrecht? - entitled 'conclusions and lessons learned' - is so valuable that it should be required reading for all future CCS project proponents anywhere in the world.

Further to the extensive literature on why and how public engagement on CCS should unfold, Xenias and Whitmarsh (2018, p.103) surveyed European-based CCS experts, including but not limited to those who engage with the public directly, for their views on the value of public engagement as a process and their use of best practices and other social science insights regarding public engagement. While the experts recognised "the importance of public engagement... for both substantive and instrumental rationales and are largely aware of the range of factors (knowledge, values, trust, etc.) influencing public engagement" there appears to remain room to improve the connection between the public engagement literature and those charged with delivering it. This is based on the findings of a relatively low salience of early and substantive engagement amongst the CCS experts.

\section{Robust decision processes}

Arvai and colleagues (Arvai et al., 2012; Bessette and Arvai, 2018; Campbell-Arvai et al., 2019) have been investigating the use of structured decision making as a decision support approach to help citizens and decision makers grasp the trade-offs involved in 
preferences for alternative energy-delivery systems. Here we use the phrase 'decision processes' in a more general sense, as the institutional mechanisms implemented by governments to arrive at credible decisions on large-scale energy projects. Specifically, the simple question to be addressed, in the context of the acceptability continuum discussed in this paper, is the extent to which stakeholders - especially members of the general public and public-interest organisations - can detect the impact of their interventions on the deliberative processes leading to final decisions and how well satisfied they might be with those results. An example of what is required in this regard is provided by the approval decision for the Shell Quest project, issued by Alberta's Energy Resources Conservation Board (2012), which notes: "[371] Second, the importance of genuine consultation. Shell said its engagement showed a genuine concern for how people felt about the project and it identified problems and potential solutions. Based on feedback from community people, project details were modified, as illustrated by the 30 reroutes of the pipeline."

One of the most important documents in this area was produced by a leading actor, DNV GL (formerly Det Norske Veritas, the well-known engineering consultancy headquartered in Norway, which has been in business for 150 years and which provides technical services to the maritime, oil and gas and energy industries (http://www.dnvgl.com/)). Issued in early 2013 and focusing on CCS projects, it is entitled CO2RISKMAN: Guidance on CCS CO2 Safety and Environment: Major Accident Hazard Risk Management (see also Larkin et al., 2019a). Among other guidance, the document

- $\quad$ suggests that as experience grows within the CCS industry it is important to actively share knowledge and learn from others. This will help ensure risk management for CCS projects is economic, effective, robust and transparent.

- Discusses communication and consultation with external and internal stakeholders: the need that this takes place during all stages of the risk management process; that this addresses issues relating to the risk itself, particularly its causes, its consequences and the measures being taken to reduce it. The goal is to be accountable and to ensure understanding for why decisions are made.

- Recognises that stakeholders make judgements about risk based on perceptions of risk (clearly linking back to the first step of the social acceptability continuum being described here); that perception can have significant impact on decisions; that communication and consultation need to facilitate "truthful, relevant, accurate and understandable exchanges of information, taking into account confidential and personal integrity" [Det Norske Veritas, (2013), Level 3, p.18].

CO2RISKMAN also includes a reference to a UK oil and gas decision support framework to improve decision making arrangements and processes and facilitate more transparent and demonstrably justifiable decisions. It is reproduced in Figure 1.

The DNV document suggests that adopting this framework should help promote decision making transparency as well as consistent stakeholder dialogue and engagement and provide assistance to firms in identifying where improvements can be made in managing health, safety and environmental risks. 
Figure 1 A decision support framework for major accident hazard safety (see online version for colours)

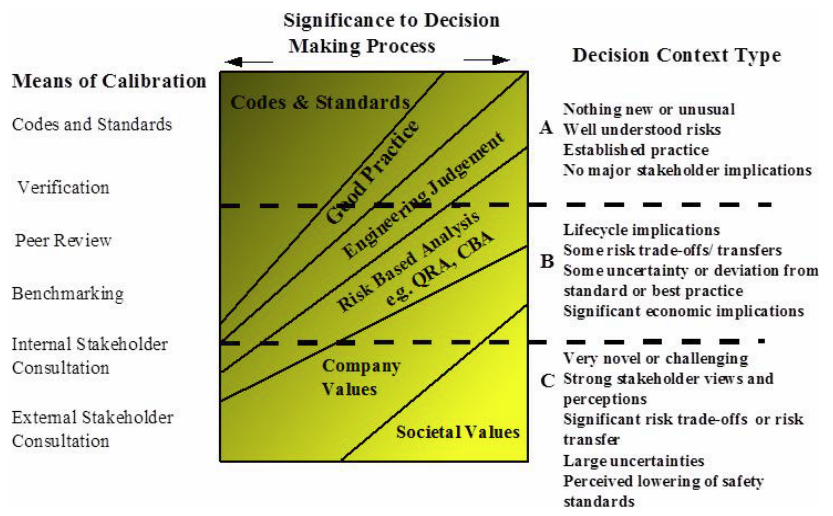

Source: Originally published by the United Kingdom Offshore Operators Association (Det Norske Veritas, 2013)

\section{Public and social acceptability (local and national)}

As suggested at the outset, public and social acceptability is the final step on the continuum we have been discussing in this paper whereby:

- Public perceptions reflect judgements by citizens on public policy issues that are informed by both access to information, prior knowledge, level of interest and underlying values.

- Effective communication involves such factors as delivery of information in a timely manner; the reliability and credibility of information, which may include, e.g., independent expert evaluation; an acknowledgement by the major actors of the legitimacy of differing perspectives on issues; and the effort made to 'translate' technical knowledge, in a credible way, into language understandable by non-experts.

- An effective public engagement strategy, which is "a key element in a successful development. An effective engagement meets the needs of the community, is initiated early in the process, is proactive and is integrated with the technical activities" (Oltra et al., 2012).

- Decision-support tools are designed to assist citizens in clarifying the judgements they make, for example, with difficult matters such as trade-offs among multiple objectives.

Of special note that throughout these first four steps, transparency would involve such factors as ease of access to information and the fullest possible disclosure of all decision inputs in risk assessment and risk management decision-making. 
- Finally, public acceptability will include an acknowledgement of the public good (need for CCS) that the projects represent, since projects must be paid for by citizens in one form or another; a strong level of comfort with the level of environmental and health risks, as assessed; and a strong level of confidence in the robustness of regulatory practices.

In an 'ideal case', adequate attention and required resources will have been deployed on all these elements, in a timely fashion, by all major actors on CCS issues (project proponents, governments and regional or national public-interest groups), but especially by governments, which have the most important responsibilities in this area from the standpoint of good public policy. Throughout all of these elements there runs one common theme, that is, the building of trust between project proponents and the public: The importance of trust has long been emphasised in the literature on risk communication and it has an obvious bearing on the possibilities for adequate public understanding and acceptability.

In a study of five cases of efforts to establish CCS projects in Europe (two in Germany, one each in the Netherlands, Poland and Spain, in which three were successful and two were not), Oltra et al. (2012, p.242)

...classified the main factors involved in community responses to CCS into six broad areas: the characteristics of the project; the engagement process; the public perceptions; the actions of the stakeholders; the characteristics of the community; and the socio-political context. All of these elements can influence the probability of generating a negative local reaction to a siting process. But no factor alone can guarantee success or failure in siting...

This emphasis on a multi-factorial explanation rules out - correctly, we think - a simple "NIMBY" phenomenon as an explanation for failure (see also Boyd, 2017; Krause et al., 2014; Lock et al., 2014; Wallquist et al., 2012). The successful operation of CCS-EOR (enhanced-oil-recovery) projects offers one substantial proof of this point. According to the MIT Sequestration database (MIT, 2018), there are currently more than two dozen EOR projects around the world, in the USA, Canada, China and elsewhere, most of which appear to have been operating for decades with little controversy, judging by the information provided on the project page descriptions in the database. The local communities involved have one characteristic in common: namely, they are very familiar with oil and gas operations; EOR thus is a simple add-on to an industrial process that they know well.

But as is already clear, the worldwide objectives of CCS, in relation to reducing $\mathrm{CO}_{2}$ emissions as part of a global climate change policy, will require many sequestration-only projects as well as those for EOR. Here too reactions among local stakeholders and communities are likely to differ according to their degree of familiarity and closeness to traditional resource development activities. Thus we would expect most people in Western Canada, including British Columbia, Alberta and Saskatchewan, to have a relatively muted response to newer CCS-sequestration projects (provided that engagement processes have been carried out well), in comparison to those which will eventually be sited in some other provinces (Boyd et al., 2017). We would expect the same muted response to be true in countries like Australia. However, the combination of much higher average population densities and a highly-involved citizenry in much of the European Union, for example, appears to indicate that the routine achievement of public acceptability for CCS projects is more challenging. With the exception of Norway (not a 
full member of the EU), just one project in the Netherlands is at an advanced stage of planning, with several others at early stages in the UK (GCCSI, 2018).

\title{
7 Overview and conclusions
}

The general public, for example in Canada, has had quite limited exposure to the many aspects of carbon capture and storage thus far. One reason is, of course, that competing issues such as the oil sands, hydraulic fracturing and new pipelines have tended to 'crowd out' CCS from public issue agendas in recent years. The other main reason is that CCS is quite new and that the most intensive interactions have occurred, primarily behind closed doors, between industry and governments. The sole sequestration-only CCS project at present in Canada, Shell Quest in Alberta, was given final approval in 2012 after an extensive, multi-year process of regulatory review and in this case there is a large amount of publicly-available documentation on the process. As we have seen in our discussion of project websites, there is a fair amount of good general information available in Canada and elsewhere. However, there remain noted gaps in Canada with respect to transparency in risk assessment and risk management (Larkin et al., 2019b).

\subsection{The transparency issue}

As shown in a number of careful analyses of the regulatory review documents for Shell Quest (Larkin et al., 2019b) a great deal of sustained effort is required in order to extract any meaningful sense of the risk assessment and management process in this case. This is because the way in which the documentary evidence is structured makes it difficult to assemble the many separate pieces into a coherent whole. And, when that task has been completed, there is still no comprehensive risk estimation for the project as a whole (i.e., there is no 'roll-up' of the different components of risk into an overall assessment).

The independent project review of the storage component of Shell Quest, managed and facilitated by the consulting firm Det Norske Veritas (2010) (now DNV GL) states:

\begin{abstract}
"Shell's risk register [which is not available publicly] does not include any reference to potential hazards that has been considered but disregarded on the basis of being insignificant. For completeness and transparency it is recommended that a register is kept for recording hazards that have been considered, but considered insignificant. This register should also include a brief explanation for why the associated hazard was judged to be insignificant... In terms of transparency, the analysis could benefit from enhancing the transparency of the probabilistic model by more clearly defining the assumptions behind the assignment of effectiveness and uncertainty scores for safeguard performance."
\end{abstract}

Further, the CSA Standard (2012, p.35) states: "For all elements of concern other than those that strictly involve the project operator's interests, the documentation shall specify the criteria by which risk is deemed acceptable or tolerable."

One can contrast this lack of a detailed, publicly-available technical risk assessment profile in the Shell Quest case with the documentation provided in the Environmental Impact Statement (EIS) for the FutureGen project in Illinois. The initial EIS, a collection of documents in excess of 3,000 pages and posted on the Internet, recorded an elaborate comparative risk characterisation for four potential sites, two in Texas and two in Illinois, 
after which the preferred site was chosen. The 'Final Environmental Impact Statement' for the preferred site in Morgan County, Illinois carried out by the US Department of Energy pursuant to the National Environmental Policy Act, remains available in its entirety - all 1,422 pages - on the internet (US Department of Energy, 2013). Standard practice in the USA for EIS documents of this type is to issue a draft report, invite public comments and hold a public hearing. The final report includes detailed agency responses to the public comments.

Canada, on the other hand, does not have legislative requirements at the provincial government level for issuing EIS documents containing a detailed record of risk assessment and risk management decision-making. But in our opinion it is a virtual certainty that the public and important stakeholders will begin to demand more and credible information on the evaluation of risk as proposals for additional CCS projects begin to proliferate.

The 'low level of public awareness and understanding' about CCS, which has been found repeatedly in many studies to date, may not matter much for the time being, since for the most part industry and governments are advancing the technologies and paying the bills without significant public involvement. But in the long run any serious lack of both information and trust may come back to haunt the future prospects of CCS. As mentioned at the outset of this paper, CCS makes sense, in both a national and global context, only if it is ultimately done on a massive scale - with commensurate costs to be borne directly by energy consumers or indirectly through government subsidies. Faced with those hefty bills, a public that is ill-informed about the need for CCS itself, or the potential environmental and health risks associated with it, may very well be unwilling to pay them.

\section{Acknowledgements}

This research was funded by Carbon Management Canada (CMC), a federally funded Network of Centres of Excellence.

\section{References}

Alberta Carbon Trunk Line (ACTL) (2018) Welcome to Enhance [online] http://www.enhanceenergy.com/ (accessed 2 October 2018).

Arvai, J., Gregory, R., Bessette, D. and Campbell-Arvai, V. (2012) 'Decision support for developing energy strategies', Issues in Science and Technology, Summer, pp.43-52 [online] https://sites.nationalacademies.org/cs/groups/dbassesite/documents/webpage/dbasse_070996.p df (accessed 10 October 2018).

Ashworth, P., Bradbury, J., Feenstra, C.F.J., Greenberg, S., Hund, G., Mikunda, T., Wade, S. and Shaw, H. (2010a) Communication/Engagement Toolkit for CCS Projects, [online] https://www.globalccsinstitute.com/publications/communication-and-engagement-toolkit-ccsprojects (accessed 2 October 2018).

Ashworth, P., Boughen, N., Mayhew, M. and Millar, F. (2010b) 'From research to action: now we have to move on CCS communication', International Journal of Greenhouse Gas Control, Vol. 4, No. 2, pp.426-433, DOI: 10.1016/j.ijggc.2009.10.012.

Ashworth, P., Bradbury, J., Wade, S., Feenstrad, C.F.J.Y., Greenberg, S., Hund, G. and Mikunda, T. (2012) 'What's in store: lessons from implementing CCS', International Journal of Greenhouse Gas Control, July, Vol. 9, pp.402-409, DOI: 10.1016/j.ijggc.2012.04.012. 
Ashworth, P., Dowd, A-M., Rodriguez, M., Jeanneret, T., Mabon L. and Howell, R. (2013) Synthesis of CCS Social Research: Reflections and Current State of Play in 2013 [online] http://hub.globalccsinstitute.com/sites/default/files/publications/115553/Synthesis-CCS-socialresearch.pdf (accessed 2 October 2018).

Bäckstrand, K., Meadowcroft, J. and Oppenheimer, M. (2011) 'The politics and policy of carbon capture and storage: framing an emergent technology', Global Environmental Change, Vol. 21, No. 2, pp.275-81, DOI: 10.1016/j.gloenvcha.2011.03.008.

Bessette, D. and Arvai, J. (2018) 'Engaging attribute tradeoffs in clean energy portfolio development', Energy Policy, Vol. 115, pp.221-229, DOI: 10.1016/j.enpol.2018.01.021.

Boyd, A.D. (2017) 'Examining community perceptions of energy systems development: the role of communication and sense of place', Environmental Communication, Vol. 11, No. 2, pp.184-204, DOI: 10.1080/17524032.2015.1047886.

Boyd, A.D., Hmielowski, J.D. and David, P. (2017) 'Public perceptions of carbon capture and storage in Canada: results of a national survey', International Journal of Greenhouse Gas Control, Vol. 67, pp.1-9, DOI: 10.1016/j.ijggc.2017.10.010.

Boyd, A.D., Liub, Y., Stephens, J.C., Wilson, E.J., Pollak, M., Peterson, T.R., Einsiedel, E. and Meadowcroft, J. (2013) 'Controversy in technology innovation: contrasting media and expert risk perceptions of the alleged leakage at the Weyburn carbon dioxide storage demonstration project', International Journal of Greenhouse Gas Control, May, Vol. 14, pp.259-269, DOI: 10.1016/j.ijggc.2013.01.011.

Bradbury, J., Greenberg, S. and Wade, S. (2011) Communicating the Risks of CCS [online] https://www.globalccsinstitute.com/sites/default/files/publications/21027/communicatingrisks-ccs.pdf (accessed 9 October 2018).

Brunsting, S., De Best-Waldhober, M., Feenstra, C.F.J.Y. and Mikunda, T. (2010) 'Stakeholder participation practices and onshore CCS: lessons from the Dutch CCS Case Barendrecht', Energy Procedia, Vol. 4, pp.6376-6383, DOI: 10.1016/j.egypro.2011.02.655.

Bui, M., Adjiman, C.S., Bardow, A., Anthony, E.J., Boston, A., Brown, S., Fennell, P.S., Fuss, S., Galindo, A., Hackett, L.A., Hallett, J.P., Herzog, H.J., Jackson, G., Kemper, J., Krevor, S., Maitland, G.C., Matuszewski, M., Metcalfe, I.S., Petit, C., Puxty, G., Reimer, J., Reiner, D.M., Rubin, E.S., Scott, S.A., Shah, N., Smit, B., Trusler, J.P.M., Webley, P., Wilcox, J. and Mac Dowell, N. (2018) 'Carbon capture and storage (CCS): the way forward', Energy and Environmental Science, Vol. 11, No. 5, pp.1062-1176, DOI: 10.1039/c7ee02342a.

Campbell-Arvai, V., Bessette, D., Kenney, L. and Arvai, J. (2019) 'Improving decision-making processes for carbon management initiatives', International Journal of Risk Assessment and Management, in this issue.

Carbon Capture and Storage Association (CCSA) (2012) Carbon Dioxide Capture and Storage in Geological Formations as Clean Development Project Activities [online] https://unfccc.int/resource/docs/2012/smsn/ngo/154.pdf (accessed 9 October 2018).

Cenovus Energy (2014) Cenovus releases Weyburn Site Assessment Findings [online] http://www.cenovus.com/news/news-releases/2011/1129-cenovus-releases-weyburnfindings.html (accessed 9 October 2018).

Chaudhry, R., Fischlein, M., Larson, J., Hall, D.M., Peterson, T.R., Wilson, E.J. and Stephens, J.C. (2013) 'Policy stakeholders' perceptions of carbon capture and storage (CCS): a comparison of four U.S. states', Journal of Cleaner Production, Vol. 52, pp.21-32, DOI: 10.1016/j.jclepro.2013.02.002

Chevron (2018) Gorgon [online] https://www.chevron.com/projects/gorgon (accessed 2 October 2018)

Cook, P.J. (2017) 'CCS research development and deployment in a clean energy future: lessons from Australia over the past two decades', Engineering, Vol. 3, No. 4, pp.477-484, DOI: 10.1016/j.eng.2017.04.014

CSA (2012) Canadian Standards Association, Standard, CSAZ741 - Geological Storage of Carbon Dioxide [online] https://www.csagroup.org/news_or_press/csa-group-and-ipac-co2-researchinc-announce-worlds-first-bi/ (purchase only). 
Daly, D., Bradbury, J., Garrett, G., Greenberg, S., Myhre, R., Peterson, T., Tollefson, L., Wade, S. and Sacuta, N. (2011) 'Road-testing the outreach best practices manual: applicability for implementing of the development phase projects by the regional carbon sequestration partnerships', Energy Procedia, Vol. 4, pp.6256-62, DOI: 10.1016/j.egypro.2011.02.639.

de Best-Waldhober, M., Brunsting, S. and Paukovic, M. (2012) 'Public concepts of CCS: understanding of the Dutch general public and its reflection in the media', International Journal of Greenhouse Gas Control, Vol. 11S, pp.S139-S147, DOI: 10.1016/j.ijggc.2012.08.016.

Det Norske Veritas (2010) Independent Project Review (IPR) of Storage Component of the QUEST Carbon Capture and Storage Project [online] https://www.energy.alberta.ca/AU/CCS/KnowledgeSP/Documents/2011/IndependentProjectR eviewofStorageComponentofCCSProject.pdf (accessed 20 September 2018).

Det Norske Veritas (2013) CO2RISKMAN, Guidance on CCS CO2 Safety and Environment, Major Accident Hazard Risk Management, Level 1, 2, 3 and 4 [online] https://www.dnvgl.com/oilgas/joint-industry-projects/ongoing-jips/co2riskman.html (accessed 6 September 2018).

DOE (2009) DOE Regional Partnership Begins Core Sampling for Large-Volume Sequestration Test [online] http://energy.gov/fe/articles/doe-regional-partnership-begins-core-samplinglarge-volume (accessed 9 October 2018).

Eiken, O., Ringrose, P., Hermanrud, C., Nazarian, B., Torp, T. and Høier, L. (2011) 'Lessons learned from 14 years of CCS operations: Sleipner, in Salah and Snøhvit', Energy Procedia, Vol. 4, pp.5541-5548, DOI: 10.1016/j.egypro.2011.02.541.

Energy Resources Conservation Board (2012) Decision: Shell Canada Limited, Application for the Quest Carbon Capture and Storage Project, Radway Field [online] https://www.aer.ca/documents/decisions/2012/2012-ABERCB-008.pdf (accessed 20 September 2018).

Equinor (2018) Climate Change [online] https://www.equinor.com/en/how-and-why/climatechange.html (accessed 3 October 2018).

European Commission (2011) 'Special Eurobarometer 364 - Public Awareness and Acceptance of $\mathrm{CO}_{2}$ Capture and Storage [online] http://ec.europa.eu/public_opinion/archives/ebs/ ebs_364_en.pdf (accessed 9 October 2018).

European Commission (2013) Communication from the Commission to the European Parliament, the Council, the European Economic and Social Committee and the Committee of the Regions, on the Future of Carbon Capture and Storage in Europe, Brussels, 27 March, $\operatorname{COM(2013)} 180 \mathrm{final}$ [online] https://ec.europa.eu/clima/sites/clima/files/lowcarbon/ccs/docs/ com_2013 180_en.pdf (accessed 9 October 2018).

Feenstra, C.F.J., Mikunda, T. and Brunsting, S. (2010) What Happened at Barendrecht? [online] https://www.globalccsinstitute.com/publications/what-happened-barendrecht (accessed 9 October 2018)

Global CCS Institute (GCCSI) (2011) Project Pioneer - Alberta Local Community Perceptions, no longer available online.

Global CCS Institute (GCCSI) (2013) Communications for Carbon Capture and Storage: Identifying the Benefits, Managing Risk and Maintaining the Trust of Stakeholders [online] https://www.globalccsinstitute.com/publications/communications-carbon-capture-and-storageidentifying-benefits-managing-risk-and (accessed 9 October 2018).

Global CCS Institute (GCCSI) (2018) Status of CCS Project Database [online] https://www.globalccsinstitute.com/projects/large-scale-ccs-projects (accessed 20 September 2018).

IEA (2010) Energy Technology Perspectives 2010: Scenarios and Strategies to 2050 [online] https://www.iea.org/publications/freepublications/publication/etp2010.pdf [online] https:/www.iea.org/media/workshops/2010/transforminginnovation/taylor.pdf (accessed 9 October 2018)]. 
IEA (2016) 20 Years of Carbon Capture and Storage [online] https://www.iea.org/publications/ freepublications/publication/20YearsofCarbonCaptureandStorage_WEB.pdf (accessed 20 August 2018).

IEAGHG (2017) CCS Deployment in the Context of Regional Developments in Meeting Long-term Climate Change Objectives, Technical Report 2017-07 [online] https://ieaghg.org/exco_docs/2017-07.pdf (accessed 17 September 2018).

Institute for European Environmental Policy (2010) Review of the Public Participation Practices for CCS and non-CCS Projects in Europe [online] https://ieep.eu/publications/ review-of-the-public-participation-practices-for-ccs-and-non-ccs-projects-in-europe (accessed 3 October 2018).

IPAC CO2 (2011a) Public Awareness and Acceptance of Carbon Capture and Storage in Canada, no longer available.

Itaoka, K., Saito, A., Paukovic, M., de Best-Waldhober, M., Dowd, A-M., Jeanneret, T., Ashworth, P. and James, M. (2012) Understanding How Individuals Perceive Carbon Dioxide: Implications for Acceptance of Carbon Dioxide Capture and Storage [online] https://www.globalccsinstitute.com/publications/understanding-how-individuals-perceivecarbon-dioxide-implications-acceptance-carbon (accessed 9 October 2018).

Johnsson, F., Reiner, D., Itaoka, K. and Herzog, H. (2009) 'Stakeholder attitudes on carbon capture and storage - an international comparison', Energy Procedia, Vol. 1, No. 1, pp.4819-26, DOI: 10.1016/j.egypro.2009.02.309.

Kefford, B., Schmeda-Lopez, D., Stringer, M., Greig, C., Smart, S., Small, M. and Wong-Parodi, G. (2018) Identifying Regionally Dependent Barriers in the Carbon Capture and Storage industry [online] https://bit.ly/2IuDdYT (accessed 4 September 2018).

Krause, R.M., Carley, S.R., Warren, D.C., Rupp, J.A. and Graham, J.D. (2014) " Not in (or under) my backyard": geographic proximity and public acceptance of carbon capture and torage facilities', Risk Anal, Vol. 34, No. 3, pp.529-40, DOI: 10.1111/risa.12119.

L'Orange Seigo, S., Arvai, J., Dohle, S. and Siegrist, M. (2014) 'Predictors of risk and benefit perception of carbon capture and storage (CCS) in regions with different stages of deployment', International Journal of Greenhouse Gas Control, June, Vol. 25, pp.23-32, DOI: 10.1016/j.ijggc.2014.03.007

Larkin, P., Leiss, W. and Krewski, D. (2019a) 'Risk assessment and management frameworks for carbon capture and storage: a global perspective', International Journal of Risk Assessment and Management, in this issue.

Larkin, P., Leiss, W. and Krewski, D. (2019b) 'The evolution of regulatory practice for CCS projects in Canada', International Journal of Risk Assessment and Management, in this issue.

Leiss, W. and Krewski, D. (2019) 'Environmental scan and issue awareness: risk management challenges for CCS', International Journal of Risk Assessment and Management, in this issue.

Lock, S.J., Smallman, M., Lee, M. and Rydin, Y. (2014) "Nuclear energy sounded wonderful 40 years ago": UK citizen views on CCS', Energy Policy, Vol. 66, pp.428-435, DOI: 10.1016/j.enpol.2013.11.024.

Mander, S., Polson, D., Roberts, T. and Curtis, A. (2011) 'Risk from $\mathrm{CO}_{2}$ storage in saline aquifers: a comparison of lay and expert perceptions of risk', Energy Procedia, Vol. 4, pp.6360-67, DOI: $10.1016 /$ j.egypro.2011.02.653.

Massachusetts Institute of Technology (MIT) (2018) Carbon Capture and Sequestration Project Database [online] http://sequestration.mit.edu/tools/projects/index.html (accessed 19 August 2018).

Monastersky, R. (2013) 'Seabed scars raise questions over carbon-storage plan', Nature, Vol. 504, No. 7480, pp.339-340 [online] https://www.nature.com/news/seabed-scars-raise-questionsover-carbon-storage-plan-1.14386 (accessed 3 October 2018). 
National Energy Technology Laboratory (NETL) (2017) Best Practices: Public Outreach and Education for Geologic Storage Projects [online] https://www.netl.doe.gov/ File\%20Library/Research/Carbon-Storage/Project-Portfolio/BPM_PublicOutreach.pdf (accessed 7 September 2018).

Oltra, C., Upham, P., Riesch, H., Boso, A., Brunsting, S., Dütschke, E. and Lis, A. (2012) 'Public responses to $\mathrm{CO}_{2}$ storage sites: lessons from five European cases', Energy and Environment, Vol. 23, Nos. 2-3, pp.227-248, DOI: 10.1260/0958-305X.23.2-3.227.

PTRC (2019) Petroleum Technology Research Centre, [online] https://ptrc.ca/index (accessed 14 May 2019).

Ringrose, P.S. (2018) 'The CCS hub in Norway: some insights from 22 years of saline aquifer storage', Energy Procedia, Vol. 146, pp.166-172, DOI: 10.1016/j.egypro.2018.07.021.

Ringrose, P.S., Mathieson, A.S., Wright, I.W., Selama, F., Hansen, O., Bissell, R., Saoula, N. and Midgley, J. (2013) 'The in Salah $\mathrm{CO}_{2}$ storage project: lessons learned and knowledge transfer', Energy Procedia, Vol. 37, pp.6226-6236, DOI: 10.1016/j.egypro.2013.06.551.

Sala, R. and Oltra, C. (2011) 'Experts' attitudes towards CCS technologies in Spain', International Journal of Greenhouse Gas Control, Vol. 5, No. 5, pp.1339-45, DOI: 10.1016/j.ijggc.2011.07.007.

Shackley, S., Reiner, D., Upham, P., de Coninck, H., Sigurthorsson, G. and Anderson, J. (2009) 'The acceptability of $\mathrm{CO}_{2}$ capture and storage (CCS) in Europe: an assessment of the key determining factors', International Journal of Greenhouse Gas Control, Vol. 3, No. 3, pp.344-56, DOI: 10.1016/j.ijggc.2008.09.004.

Shell Canada Ltd. (2018) Quest Carbon Capture and Storage [online] https://www.shell.ca/en_ca/about-us/projects-and-sites/quest-carbon-capture-and-storageproject.html (accessed 2 October 2018).

Terwel, B.W., Ter Mors, E., Daamen, D.D.L. (2012) 'It's not only about safety: beliefs and attitudes of 811 local residents regarding a CCS project in Barendrecht', International Journal of Greenhouse Gas Control, Vol. 9, pp.41-51, DOI: 10.1016/j.ijggc.2012.02.017.

United Nations Framework Convention on Climate Change (UNFCCC) (2015) Adoption of the Paris Agreement, FCCC/CP/2015/L.9 [online] http://unfccc.int/resource/docs/2015/cop21/ eng/109.pdf (accessed 16 August 2018).

US Department of Energy (2013) EIS-0460: Final Environmental Impact Statement [online] http://energy.gov/nepa/downloads/eis-0460-final-environmental-impact-statement (accessed 30 September 2018).

Wallquist, L., L’Orange Seigo, S., Visschers, V.H.M. and Siegrist, M. (2012) 'Public acceptance of CCS system elements: a conjoint measurement', International Journal of Greenhouse Gas Control, Vol. 6, pp.77-83, DOI: 10.1016/j.ijggc.2011.11.008.

World Resources Institute (2010) Guidelines for Community Engagement in Carbon Dioxide Capture, Transport and Storage Projects [online] http://pdf.wri.org/ ccs_and_community_engagement.pdf (accessed 3 October 2018).

Xenias, D. and Whitmarsh, L. (2018) 'Carbon capture and storage (CCS) experts' attitudes to and experience with public engagement', International Journal of Greenhouse Gas Control, Vol. 78, pp.103-116, DOI: 10.1016/j.ijggc.2018.07.030.

\section{Notes}

1 The transport component of the value chain is not considered to be a new technology. 